\title{
Common Cerambycid Pheromone Components as Attractants for Longhorn Beetles (Cerambycidae) Breeding in Ephemeral Oak Substrates in Northern Europe
}

\author{
Mikael A. Molander ${ }^{1}$ (D) - Inis B. Winde ${ }^{1} \cdot$ Joseph Burman $^{2} \cdot$ Franklin N. Nyabuga $^{3} \cdot$ Tobias U. T. Lindblom $^{4}$. \\ Lawrence M. Hanks ${ }^{5}$ - Jocelyn G. Millar ${ }^{6}$ - Mattias C. Larsson ${ }^{1}$
}

Received: 29 March 2019 /Revised: 31 May 2019 / Accepted: 12 June 2019 / Published online: 28 June 2019

(C) The Author(s) 2019

\begin{abstract}
Longhorn beetles are ecologically important insects in forest ecosystems as decomposers of woody substrates, microhabitat engineers, and as components of forest food webs. These species can be greatly affected both positively and negatively by modern forestry management practices, and should be monitored accordingly. Through headspace sampling, coupled gas chromatographyelectroantennography, gas chromatography-mass spectrometry, and field bioassays, we identified two compounds, 2-methyl-1butanol and 3-hydroxy-2-hexanone, that constitute aggregation-sex pheromone attractants of three cerambycid species which breed primarily in different types of fresh, recently dead oak wood in Northern Europe: Pyrrhidium sanguineum (L.), Phymatodes alni ssp. alni (L.), and Phymatodes testaceus (L.) (Cerambycinae: Callidiini). Analyses of headspace volatiles collected from live insects indicated that the male-produced aggregation-sex pheromone of $P$. sanguineum is a 1-15:100 blend of $(R)$-2-methyl-1-butanol and $(R)-3$-hydroxy-2hexanone, whereas the corresponding ratios for $P$. alni were 70-110:100. In field bioassays, adult $P$. sanguineum and $P$. alni were significantly attracted to multiple blends with varying ratios of the two compounds. When tested individually, the compounds were minimally attractive. In contrast, adult $P$. testaceus exhibited nonspecific attraction to both of the individual compounds and to different blends, despite the hydroxyketone not being part of its pheromone, which consists of $(R)-2$-methyl-1-butanol alone. Overall, our results suggest that a blend of 50:100 of racemic 2-methyl-1-butanol and 3-hydroxy-2-hexanone is appropriate for parallel, cost-efficient pheromone-based monitoring of all three species. In particular, these species could serve as useful indicators of how modern forestry practices affect a whole guild of saproxylic insects that require ephemeral deadwood substrates for successful breeding.
\end{abstract}

Keywords Semiochemical $\cdot(R)$-2-Methyl-1-butanol $\cdot(R)$-3-Hydroxy-2-hexanone $\cdot$ Monitoring $\cdot$ Biodiversity $\cdot$ Red List

\section{Introduction}

Longhorn beetles (Cerambycidae) constitute important components of forest ecosystems worldwide, where they contribute to the decomposition of dead wood, create microhabitats for other organisms, and are important components of forest food webs (Buse et al. 2008; Hogstad and Stenberg 1997). Longhorn beetles typically breed in dying or recently
Mikael A. Molander and Inis B. Winde joint first authorship

Electronic supplementary material The online version of this article (https://doi.org/10.1007/s10886-019-01082-4) contains supplementary material, which is available to authorized users.

Mikael A. Molander

mikael.molander@slu.se

1 Unit of Chemical Ecology, Department of Plant Protection Biology, Swedish University of Agricultural Sciences, Box 102, Sundsvägen 14, 23053 Alnarp, Sweden

2 Present address: Ecology Research Group, Canterbury Christ Church University, North Holmes Road, Canterbury, Kent CT1 1QU, United Kingdom
3 Present address: Department of Biological Sciences, University of Embu, P.O. Box 6, 60100 Embu, Kenya

4 Present address: Department of Crop Production Ecology, Swedish University of Agricultural Sciences, Box 7043, 750 07 Uppsala, Sweden

5 Department of Entomology, University of Illinois at Urbana-Champaign, Urbana, IL 61801, USA

6 Departments of Entomology and Chemistry, University of California, Riverside, CA 92521, USA 
dead wood, but their larval habitats may also include healthy living wood, as well as decaying above- or below-ground wood, and the stems of living herbs and bushes (Linsley 1959). Some longhorn beetles are economically important pests in forestry or agriculture, with high potential to become invasive pest species (Haack 2017). As with many other insect taxa, the potential of some species to become pests has provided the primary motivation to identify pheromones for both endemic and invasive longhorn beetles (Allison et al. 2004; Hanks and Millar 2016).

In the last decade, the pheromones of a small number of insect species have also been exploited for conservation purposes, with pheromone-baited traps being used to monitor the presence of rare and threatened species that are otherwise difficult to survey (Larsson 2016). This includes some longhorn beetles, such as species from the genera Prionus (Barbour et al. 2011), Tragosoma (Ray et al. 2012), Desmocerus (Ray et al. 2014), and Rosalia (Žunič Kosi et al. 2017). Overall, there is an enormous untapped potential to use longhorn beetles as indicator species in forestry and forest biodiversity conservation, by means of pheromone-based monitoring. Many species are currently in decline due to the scarcity of deadwood resources in modern managed forests and in agricultural landscapes (Jeppsson et al. 2010; Lindhe et al. 2010). Still other species that are not themselves directly threatened at present constitute important food resources for other threatened organisms such as woodpeckers (Hogstad and Stenberg 1997), and could therefore be useful for monitoring the general state of forest food webs at local and landscape levels. This includes a whole guild of longhorn beetles that breed in ephemeral woody substrates such as fresh, recently killed trunks, stumps, and branches, which are only suitable as larval substrates for short periods of time, typically 1-2 years (Ehnström and Holmer 2007; Linsley 1959).

Longhorn beetles breeding in ephemeral fresh woody substrates have high potential to reflect relatively fast dynamic processes typical of managed forest ecosystems. They thus represent a complementary conservation target to the saproxylic insects that breed in old trees or very coarse, late-successional woody materials, and which are a major focus of current deadwood conservation efforts (e.g., Milberg et al. 2016; Ranius and Jansson 2000; Seibold et al. 2015). Their ability to exploit relatively young and quickly regenerating deadwood resources would seemingly make these longhorn beetles unlikely targets of conservation concern. However, in modern forestry, even early successional species may suffer from declining breeding substrates due to the efficient harvesting of residue materials from logging as biofuel resources, which could make even small woody debris such as twigs and branches a limiting resource in modern production forests. Of equal or even greater concern might be the removal of woody debris for biofuel after colonization by woodborers, so that the host resource becomes a population sink for these species (Hedin et al. 2008).
The cerambycid Pyrrhidium sanguineum (L.) (Cerambycinae: Callidiini) is a species representative of the guild of longhorn beetles described above. It has a relatively narrow substrate range and primarily breeds in fresh, recently dead, medium-sized logs and branches of oak (Ehnström and Holmer 2007). Although not threatened from a global or European perspective, $P$. sanguineum is considered a rare species in Northern Europe, including Sweden, where it is nationally red listed as Near Threatened (ArtDatabanken 2015), and Denmark, where it is red listed as Vulnerable (Wind and Pihl 2010). It could thus have high potential to function as an indicator species of scarce ephemeral deadwood resources, provided it can be monitored efficiently with pheromone traps. The pheromone of $P$. sanguineum had previously been reported as a blend of $(R)$-3-hydroxy-2-hexanone (main component), $(2 S, 3 R)-2,3$-hexanediol and ( $2 R, 3 R)$-hexanediol, that was significantly attractive to unmated females in wind tunnel assays (Fettköther 1995; Schröder et al. 1994). However, to our knowledge no field trapping studies have demonstrated attraction of $P$. sanguineum to a blend of these compounds.

Here we summarize research that reinvestigated the composition of the aggregation-sex pheromone of $P$. sanguineum by collection of headspace odors from live beetles, and analysis of the resulting extracts by gas chromatographyelectroantennographic detection (GC-EAD) and coupled gas chromatography-mass spectrometry (GC-MS), followed by field bioassays of possible pheromone components. Similar to previous work, our experiments confirmed that $(R)-3$-hydroxy-2-hexanone was the main pheromone component of the species, but we also found that $(R)$-2-methyl-1-butanol is a previously unreported minor pheromone component, and that the blend of these two compounds constitutes the maleproduced aggregation-sex pheromone of $P$. sanguineum. We also demonstrate that the same compounds function as the aggregation-sex pheromone of the closely related species Phymatodes alni ssp. alni (L.) (henceforth referred to as P. alni). Further, we observed that a third species, Phymatodes testaceus, was significantly attracted to both 3hydroxy-2-hexanone and 2-methyl-1-butanol as single compounds, and to blends of these, although the species' pheromone has previously been identified as $(R)$-2-methyl-1-butanol alone (Hanks et al. 2019).

\section{Materials and Methods}

\section{Collection of Insects for Experiments}

In the spring of 2011 and 2012 freshly cut branches of pedunculate oak (Quercus robur L.), were placed at two sites in southeastern Sweden, one site within Ecopark Hornsö in Kalmar County (decimal degrees: 57.0280 N, 16.1638 E) and one site at Gö nature reserve in Blekinge County (DD: 
56.1273 N, 15.3092 E). The fresh substrates were intended to attract females of early successional longhorn beetles that are dependent on this substrate for oviposition. The wood material was collected in the autumn of each year and brought back to the Alnarp Campus to rear out any longhorn beetles. Additional oak substrates (twigs and branches) were taken from a stack of biofuel material in the winter of 2015 at Hornsö Ecopark (DD: 57.0202 N, 16.1702 E).

The dead wood was stored outdoors until it was brought inside in portions during late winter and held in ventilated plastic containers or fine mesh cages in the greenhouse facilities to collect emerging adult beetles. Adults of $P$. sanguineum primarily emerged from the wood collected in 2011 and 2012, i.e., from medium-sized branches 5$15 \mathrm{~cm}$ in diameter, whereas $P$. alni only emerged from thin twigs ( $\sim 1-3 \mathrm{~cm}$ in diameter) collected in 2015. In total, $>600$ $P$. sanguineum and $341 P$. alni emerged. Randomly selected subsets of $\sim 35$ individuals of each species were used for collection of headspace volatiles (see below).

The beetles were sexed and males and females were held separately in plastic jars containing pieces of fresh oak branches and water-soaked pieces of paper to provide moisture, either in a refrigerator at $\sim 8{ }^{\circ} \mathrm{C}$ or in a climate controlled chamber at $25{ }^{\circ} \mathrm{C}, 70 \% \mathrm{RH}$, with a $12.5: 11.5 \mathrm{~L} / \mathrm{D}$ cycle (8:30 AM to 9 PM). Males and females of P. sanguineum were easily distinguished by the relative length of the antennae. The antennae of males extend beyond the tip of the abdomen, while the antennae of females do not reach the tip of the abdomen (Hansen 1966). To sex the much smaller species $P$. alni, we placed pairs of beetles in small containers and observed if copulation was attempted. Normally, when a male and female were placed together, copulation was initiated immediately after the male first touched the female with his antennae. Pairs that attempted copulation were quickly separated and transferred to a plastic jar containing other individuals of the same sex. Individuals that made physical contact but did not attempt to copulate were excluded, as were beetles that had not made contact after $\sim 0.5 \mathrm{~min}$.

\section{Collection of Insect-Produced Volatiles}

Volatile compounds from $P$. sanguineum and $P$. alni were collected from the headspace of beetles held in $200 \mathrm{ml}$ Pyrex ${ }^{\circledR}$ glass bottles with plastic lids sealed with Teflon ${ }^{\circledR}$ lining. Males and females were held in separate bottles (and an empty control bottle was also used for $P$. alni, but not for $P$. sanguineum). Two holes were drilled through each lid to accommodate air inlets and outlets. Before collection, the bottles and lids were rinsed sequentially with water, ethanol, and acetone and allowed to dry overnight. Air was drawn through each bottle at a rate of $\sim 0.2 \mathrm{l} / \mathrm{min}$ using an air pump (model PM 10879 NMP 03, KNF Neuberger, Freiburg, Germany). Incoming air was purified by passage through a bed of granulated charcoal in a Teflon ${ }^{\circledR}$ tube, held in place with polypropylene wool plugs (Supelco/Sigma-Aldrich, Munich, Germany) and short pieces of smaller Teflon ${ }^{\circledR}$ tubing (length $2 \mathrm{~mm}$, inner $\varnothing 1.5 \mathrm{~mm}$ ), inserted into the main column on both sides of the adsorbent material. Air was pulled from the bottle through a bed of $25 \mathrm{mg}$ Porapak $^{\mathrm{TM}} \mathrm{Q}$ (mesh size 50-80, Supelco/Sigma-Aldrich) in a Teflon ${ }^{\circledR}$ tube (length $50 \mathrm{~mm}$, inner $\varnothing 3 \mathrm{~mm}$ ) and secured as already described. Both the charcoal filters for incoming air and the collectors were rinsed thoroughly with hexane and acetone, and then air-dried to allow the solvent to evaporate before use. Groups of 4 to 10 male and female beetles were put in separate bottles, and collections were run in a climate-controlled chamber at $25^{\circ} \mathrm{C}$ for 4-6 h between 10 AM and 6 PM, which encompassed the normal diel activity period of the two species (MAM, pers. obs.). After aeration, the beetles were released back into the containers with each sex. Thus, mixtures of new and previously aerated individuals were used in subsequent collections. A total of five series of collections with $P$. sanguineum and two collections with $P$. alni were performed, with each series generating a sample from males and females respectively (and for $P$. alni also a blank control sample). Trapped volatiles were eluted from collectors with $2 \times 150 \mu \mathrm{l}$ of redistilled hexane, and samples were stored in glass vials at $-18^{\circ} \mathrm{C}$ until used for analyses.

\section{Electrophysiology}

Antennal responses of male and female $P$. sanguineum to the headspace samples from both sexes were recorded using coupled gas chromatography-electroantennographic detection (GC-EAD). Two $\mu$ l of the aeration samples were injected into a GC (model 7890A, Agilent Technologies, Palo Alto, CA, USA) in splitless mode with an injector temperature of $225^{\circ} \mathrm{C}$ (split vent opened after $0.5 \mathrm{~min}$ ). The $\mathrm{GC}$ was fitted with a DB-WAX capillary column $(30 \mathrm{~m} \times 0.25 \mathrm{~mm}$ inner $ø$, d.f. $0.25 \mu \mathrm{m} ; \mathrm{J} \& \mathrm{~W}$ Scientific, Folsom, CA, USA), and eluting compounds were detected with a flame ionization detector (FID). Carrier gas was hydrogen at a constant flow rate of $2.1 \mathrm{ml} / \mathrm{min}$. The $\mathrm{GC}$ oven was programmed from $30^{\circ} \mathrm{C}$, with a $3 \mathrm{~min}$ hold, and then increased at $20^{\circ} \mathrm{C} / \mathrm{min}$ to $225^{\circ} \mathrm{C}$, and was held for $10 \mathrm{~min}$. The column effluent was split with a $3 \mathrm{D} /$ 2 low dead volume four-way-cross (Gerstel, Mülheim, Germany), $27.6 \mathrm{kPa}$ of nitrogen was added through the extra arm, and the resulting effluent was split 1:1 between the FID and the EAD. The GC effluent capillary for the EAD passed through a transfer line (ODP-3, Gerstel), which tracked the GC oven temperature, into a glass tube $(30 \mathrm{~cm}$ length $\times$ $0.8 \mathrm{~cm}$ inner $\varnothing)$, where it was diluted with a charcoal-filtered, humidified airstream $(1.0 \mathrm{~L} / \mathrm{min})$.

Antennae were excised using microscissors at the first antennal segment near the head of the beetle and mounted with electrode gel (article 1330, CefarCompex, Malmö, Sweden) 
onto a forked electroantennographic multi-probe (Syntech, Kirchzarten, Germany). The complete beetle antenna was positioned $0.5 \mathrm{~cm}$ from the outlet of the effluent tube. Signals from the antenna and the GC-FID were recorded simultaneously with a Syntech IDAC-2 digital converter and Syntech GCEAD 3.1 software. Male-produced extracts were run with antennae from 7 males and 10 females, and femaleproduced extracts were run with antennae from 7 males and 6 females. All extracts of volatiles from males and females of $P$. sanguineum were analyzed with GC-EAD, using at least one antenna for each extract.

\section{Identification of Potential Pheromone Components}

After detection of electrophysiologically active compounds at Alnarp Campus, headspace extracts from P. sanguineum were analyzed by GC-MS at UC Riverside on a medium polarity DB-17 column $(30 \mathrm{~m} \times 0.25 \mathrm{~mm}$ inner $\varnothing$, d.f. $0.25 \mu \mathrm{m}$; J\&W Scientific) mounted in a Hewlett-Packard 6890 GC (HP, now Agilent Technologies) coupled to an HP 5973 MS. The MS was operated in electron impact ionization mode (EI, $70 \mathrm{eV}$ ), with a scan range of $40-400 \mathrm{~m} / \mathrm{z}$, and transfer line temperature of $250{ }^{\circ} \mathrm{C}$. Sample aliquots $(1 \mu \mathrm{l})$ were injected in splitless mode (injector temp $250{ }^{\circ} \mathrm{C}$, split vent opened after $0.5 \mathrm{~min}$ ), with the oven programmed from $40{ }^{\circ} \mathrm{C}$ for $1 \mathrm{~min}$, then $10{ }^{\circ} \mathrm{C} / \mathrm{min}$ to $280{ }^{\circ} \mathrm{C}$, hold for $10 \mathrm{~min}$. Helium carrier gas was used (linear flow rate, $37 \mathrm{~cm} / \mathrm{s}$ ). Injections were initially made with an injector temp of $250^{\circ} \mathrm{C}$, and then repeated with a temp of $125^{\circ} \mathrm{C}$ to minimize isomerization of the thermally labile hydroxyketones.

The absolute configurations of beetle-produced compounds were determined by analyses of extracts on a chiral stationary phase Cyclodex B GC column $(30 \mathrm{~m} \times 0.25 \mathrm{~mm}$ inner $\varnothing$, d.f. $0.25 \mu \mathrm{m}$; J\&W Scientific). Samples were injected split (split ratio $\sim 20: 1$ ), with a head pressure of $172 \mathrm{kPa}$. The oven was programmed from $50{ }^{\circ} \mathrm{C}$ for $1 \mathrm{~min}$ or in some analyses for 2-methyl-1-butanol for $5 \mathrm{~min}$, then $3{ }^{\circ} \mathrm{C}$ per min to $220{ }^{\circ} \mathrm{C}$, hold for $10 \mathrm{~min}$. The injector temperature was set at $150{ }^{\circ} \mathrm{C}$ to minimize isomerization of the hydroxyketones. Samples were injected alone, and then admixed with the racemates of authentic standards to determine which of the two peaks from the racemate was increased by the insect-produced enantiomer.

In 2015, when volatiles were collected from $P$. alni, extracts of this species were first analyzed by GC-MS at Alnarp and then with the same methods as described above at UC Riverside. The GC-MS analyses of extracts from males and females at Alnarp were performed by injecting $2 \mu \mathrm{l}$ of each sample in splitless mode onto a $6890 \mathrm{~N}$ GC interfaced to a 5975 MS (both Agilent Technologies). The GC was fitted with an HP-5 ms capillary column $(60 \mathrm{~m} \times 0.25 \mathrm{~mm}$ inner $\varnothing$, d.f. $0.25 \mu \mathrm{m}$, Agilent Technologies). Helium was the carrier gas at a constant flow rate of $1.8 \mathrm{ml} / \mathrm{min}$. The injector temperature was $225{ }^{\circ} \mathrm{C}$ (split vent opened after $0.5 \mathrm{~min}$ ) and transfer line temperature was $150{ }^{\circ} \mathrm{C}$. The inlet pressure was $172 \mathrm{kPa}$ and the oven temperature was initially held at $30{ }^{\circ} \mathrm{C}$ for $3 \mathrm{~min}$, thereafter increasing by $8{ }^{\circ} \mathrm{C} / \mathrm{min}$ to $260{ }^{\circ} \mathrm{C}$, with a $10 \mathrm{~min}$ hold. The mass spectrometer was set with a $7 \mathrm{~min}$ solvent delay and a scan range of $29-400 \mathrm{~m} / \mathrm{z}$. Spectra were taken in EI mode at $70 \mathrm{eV}$.

Sex-specific compounds were recognized by visual comparison of the chromatograms from males and females, and by using the overlay function in the Agilent ChemStation software. Tentative identification of the potential pheromone compounds was performed by matching their mass spectra to those in database libraries (NIST05, NIST11, and Wiley275) and/or by comparison with retention times and mass spectra of authentic standards. Identifications were then confirmed by injections of standards (except 2,3-hexanedione for $P$. alni). For $P$. sanguineum, relative ratios of pheromone compounds were calculated based on peak integration data from FID chromatograms from the GC-EAD analyses, whereas peak integration data from the total ion chromatograms from GC-MS analyses was used for P. alni (Alnarp laboratory). In the extracts from $P$. alni, we also observed that the peak of 3-hydroxy-2-hexanone included 2-hydroxy-3-hexanone when analyzed at the Alnarp campus, but subsequent analysis at Riverside with lower analysis temperatures showed that this was likely due to thermal rearrangement and that a representative insect extract contained only a trace of 2-hydroxy-3hexanone.

\section{Sources of Chemicals}

Samples of $(R)$ - and $(S)$-3-hydroxy-2-hexanone for comparison with the insect-produced compounds were available from previous work (Lacey et al. 2007). Racemic 2-methyl-1butanol and its $(S)$-enantiomer, and 2,3-hexanedione were purchased from Aldrich Chemical Co. (Milwaukee, WI, USA), and $(R)$-2-methyl-1-butanol was prepared by reduction of $(R)$ 2-methylbutanoic acid as described in Hanks et al. (2018). 1Hexanol (reagent grade 98\%, CAS 111-27-3, Sigma-Aldrich, Hamburg, Germany) and racemic 2-methyl-1-pentanol (99.8\%, CAS 105-30-6, Dr. Ehrenstorfer GmbH, Augsburg, Germany) were purchased to confirm the identities of trace compounds in extracts from P. alni. For the bioassays, we purchased racemic 2-methyl-1-butanol $(\geq 99 \%$, CAS 137 32-6, Sigma-Aldrich, Hamburg, Germany) and racemic 3hydroxy-2-hexanone (CAS 54123-75-0, Bedoukian Research, Danbury, CT, USA).

\section{Field Bioassays}

Beetles were trapped with custom-built flight-intercept traps (Molander et al. 2019). Briefly, the traps had two cross-vane panels with a plastic funnel suspended below them, with the 
spout of the funnel protruding into the collecting jar at the bottom of the trap, and a flat top-cover for protection from rain. To maximize trapping efficiency and retention of captured beetles, the panels and the inside of the funnel were painted with a polytetrafluoroethylene dispersion $(60 \mathrm{wt} \%$ in $\mathrm{H}_{2} \mathrm{O}$, Fluon ${ }^{\circledR}$; Sigma-Aldrich, St. Louis, Missouri, USA), diluted 1:1 with water (Graham and Poland 2012). Propylene glycol ( $\sim 0.25 \mathrm{~L}$ per trap) was used as a killing agent and preservative. In 2013, traps were suspended from tree branches at approximately breast height. In 2017, we used steel reinforcing bar posts to hang the traps at about the same height above ground.

Traps were deployed in linear transects, spaced $\sim 10 \mathrm{~m}$ apart within replicates, with one treatment of each type per replicate assigned randomly at deployment. The traps were serviced at intervals of 2-4 wk., with treatment positions re-randomized at every visit. When collecting jars were emptied, the propylene glycol was filtered to separate the insects, and then reused. Trap samples were initially stored at $4{ }^{\circ} \mathrm{C}$, then transferred to $70 \%$ ethanol for long-term storage after sorting their contents. Voucher specimens will be donated to the entomological collection of the Biological Museum, Lund University, Sweden.

Traps were baited with dispensers made from polyethylene zip-lock bags $\left(\right.$ Grippie $^{\circledR}$ Light Nr-02, $5.5 \times 6.5 \mathrm{~cm} \times 40 \mu \mathrm{m}$, b.n.t. Scandinavia AB, Arlöv, Sweden). After loading, bags were sealed and suspended with metal wire near the center of the cross-vanes of the trap without puncturing the bag. Lures were loaded with $0.5 \mathrm{ml}$ of isopropanol containing different amounts of putative pheromone components (see below), whereas controls were loaded with $0.5 \mathrm{ml}$ isopropanol alone.

Bioassay 1 (2013) included an isopropanol control and different amounts (mg) of racemic 2-methyl-1-butanol and racemic 3-hydroxy-2-hexanone (with the \% of 2-methyl-1butanol in relation to 3-hydroxy-2-hexanone shown in parentheses) in ratios of 0:50 (0\%), 1:50 (2\%), 2.5:50 (5\%), 5:50 (10\%), 10:50 (20\%), and 50:0 (single component). The bioassays included four blocks of traps (spatial replicates) at Gö nature reserve, which were deployed between 5 May and 12 August 2013. The traps were emptied and the pheromone lures were replaced on 20 May, 31 May, 5 July, and 12 August, creating four separate sampling periods.

Bioassay 2 (2017) was similar to bioassay 1, but with a different range of ratios of 2-methyl-1-butanol to 3-hydroxy2-hexanone, to cover the whole range that was found in the extracts of both $P$. sanguineum and $P$. alni, as follows (in $\mathrm{mg}$, in 0.5 ml isopropanol): 0:50 (0\%), 10:50 (20\%), 25:50 (50\%), 40:50 (80\%), 50:0 (single component), and a control ( $0.5 \mathrm{ml}$ isopropanol alone). The bioassays included six blocks (spatial replicates) of traps at Ecopark Hornsö that were deployed on 30 April. The traps were emptied and lures were replaced on 20 May, 11 June, 2 July, and 24 July.

Trapped cerambycids were identified using the key by Ehnström and Holmer (2007). We also examined the sex ratios of the three different species in subsets of the trap catches from bioassay 2 . Males and females of the two larger species, $P$. sanguineum and $P$. testaceus, were separated based on the relative length of the antennae in relation to the body length (males have noticeably longer antennae than females), but a subset of about 20 individuals of each species were also dissected and their genitalia examined to verify that the length of the antennae was a consistently valid character for separation of the sexes. For the small species P. alni, we dissected all individuals in the subset and studied their genitalia.

\section{Statistical Analysis}

The datasets from the bioassays exhibited heteroscedasticity and beetle numbers were not normally distributed. Further, trap catches were strongly influenced by trapping site (spatial replicate) and the defined annual activity periods of the beetles (temporal replicates). To account for these effects, we analyzed the data with Generalized Linear Mixed Models (GLMMs) and multiple post hoc comparisons (Supplementary Tables 1 and 2). The models compared how the response variable (catch per trap) depended on treatment (fixed factor), and included replicate (site) and trapping period (temporal replicate) as random effects. First, we fitted a GLMM to each of the six datasets using the Poisson distribution (link function: $\log _{e}$ ) and calculated the dispersion statistic $(\varphi)$ for each model using Pearson residuals. Three models showed negligible over- or underdispersion $(P$. sanguineum $2013 \varphi=1.14$, P. alni $2013 \varphi=0.51$, P. testaceus $2017 \varphi=$ 1.28), with no need for model corrections. However, three of the models showed overdispersion (P. testaceus $2013 \varphi=$ 1.69, P. sanguineum $2017 \varphi=9.04$, and P. alni $2017 \varphi=$ 5.27). For these three models, we exchanged the Poisson distribution for a negative binomial distribution (link function $\log _{e}$ ). The major inferences (significant differences) remained nearly identical, with the exception that the treatment with 3hydroxy-2-hexanone as a single component was not significantly different from the control in 2013 for P. testaceus when the negative binomial distribution was used $(P=0.069)$. New dispersion statistics were calculated for the models based on the negative binomial distribution $(\varphi=0.94, \varphi=0.62$ and $\varphi=0.86$, respectively), and deemed acceptable.

After fitting the models, we compared the treatments by multiple pairwise post hoc tests using least squares means (Tukey's HSD test, Supplementary Table 2). All calculations were performed in $\mathrm{R}$ version 3.5.1 for Windows (R Core Team 2018), with the lme4 package for GLMMs (Bates et al. 2015), and the emmeans package (Lenth 2018). Statistical significance was defined as probability values $(P)$, or adjusted probability values $\left(P_{a}\right)$ for post hoc tests, of less than 0.05 .

Sampling periods (temporal replicates) or individual sites (spatial replicates) where no beetles of the focal species were captured in any trap were excluded from the analyses. Further, 
in four cases, the control treatments did not capture any beetles at all throughout the season. In order to allow for the models to be fitted, we inserted an artificial observation of one individual to the control that belonged to the spatial and temporal replicate where the other treatments had captured the highest total number of individuals (see Supplementary Table 1). Similarly, three other treatments for $P$. alni in 2013 only contained zero observations, and we inserted an artificial observation of one individual into each of these three treatments with the same method as for the controls with only zero counts. Occasionally, stray individuals were captured outside of the main activity period of the species (one $P$. alni and one $P$. testaceus respectively in 2013; one $P$. sanguineum and nine individuals of $P$. alni in 2017, all captured with blend treatments). Because these beetles either were the only individuals captured during a whole temporal replicate, or were caught in much smaller numbers than what was observed during their main flight period respectively (P. alni in 2017), we excluded these captures from data analyses because their inclusion only served to extend the variance unnecessarily. The captures mentioned above also were not included in the total catches or the figures (see Results).

\section{Results}

\section{Identification of Insect-Produced Volatiles}

In GC-EAD analyses, two compounds present in all headspace collections from males of $P$. sanguineum elicited responses from 5 of 7 antennae of males and 5 out of 10 antennae of females (Fig. 1). In subsequent GC-MS analyses, the two compounds were identified as 3-hydroxy-2-hexanone and 2-methyl-1-butanol (Fig. 2), and the absolute configurations of both compounds were determined to be $(R)$. No other compounds in the extracts of males elicited any consistent responses from antennae of either sex. Corresponding analyses with extracts of females resulted in no consistent responses from antennae of males or females, and none of the extracts from females contained 3-hydroxy-2-hexanone or 2-methyl1-butanol. Based on five independent collections from male beetles, $(R)$-3-hydroxy-2-hexanone was the major component, with $(R)$-2-methyl-1-butanol present in quantities varying from 1 to $15: 100$ (mean 7:100) of the major component. In addition, 2,3-hexanedione was consistently present in the headspace collections from male $P$. sanguineum at a mean ratio of 6:100 to $(R)$-3-hydroxy-2-hexanone.

Analyses of headspace volatiles from $P$. alni demonstrated that males produced the same two compounds as males of $P$. sanguineum, $(R)$-3-hydroxy-2-hexanone and $(R)$-2-methyl-1-butanol, which were not detected in samples from females (Fig. 3). The ratio of $(R)$-2-methyl-1-butanol to $(R)-3$ hydroxy-2-hexanone was 70:100 and 110:100 in two extracts from males (mean ratio: 90:100). In both extracts, three additional male-specific compounds were detected in minor $(2,3-$ hexanedione; mean ratio 5:100) or trace quantities (2-methyl1-pentanol; mean ratio 2:100 and 1-hexanol; mean ratio 1:100). No female-specific compounds were detected in the extracts of females, nor were any compounds common to both sexes detected in any of the insect extracts, but missing in the blank control headspace collections.

No live specimens of $P$. testaceus were collected from the emergence cages, although 21 dead specimens were found when the boxes were cleaned out. Thus, headspace extracts were not available for analysis.

\section{Field Bioassays}

In the first bioassay (2013), a total of 172 P. sanguineum were captured. Neither of the individual compounds was attractive versus the control, but blends with 2-methyl-1-butanol: 3hydroxy-2-hexanone ratios from 2.5:50 to $10: 50 \mathrm{mg}$ were significantly more attractive than the control or the individual

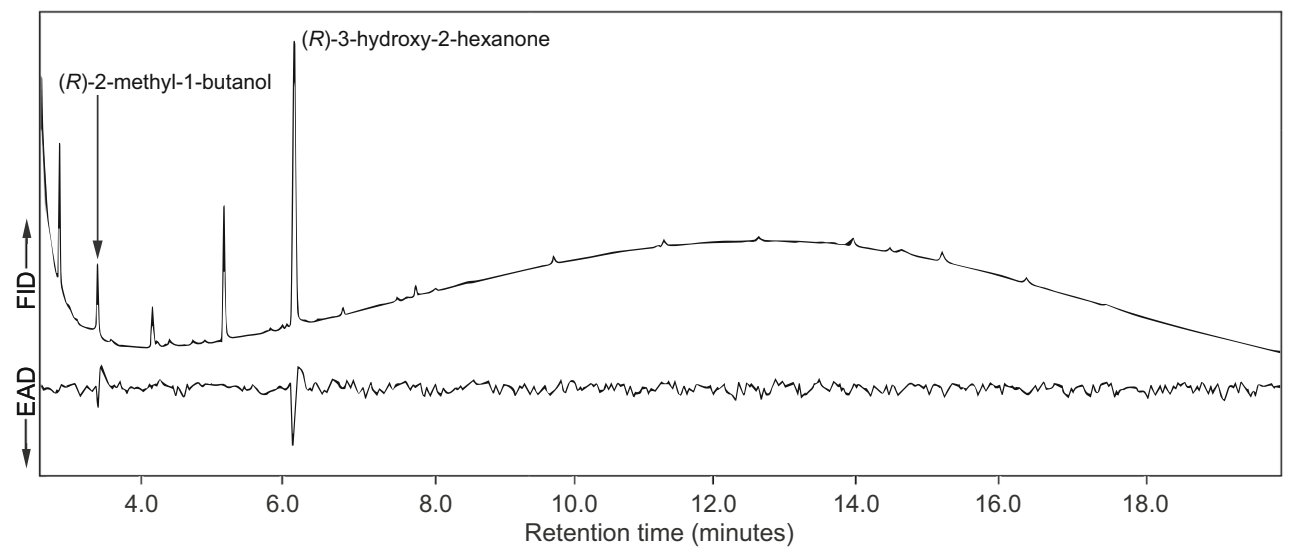

Fig. 1 Representative coupled gas chromatography-electroantennogram detection analysis of extracts of headspace volatiles from males of $P$. sanguineum, using an antenna from a male beetle of the same species. Antennae consistently responded to two compounds in these extracts, identified as (R)-2-methyl-1-butanol and (R)-3-hydroxy-2-hexanone. Analogous responses were elicited from antennae of females when stimulated with the same extracts 
Fig. 2 GC-MS analysis of extracts of headspace volatiles from male (top trace) and female (bottom, inverted trace)

P. sanguineum (HP-5 MS column). Three insect-produced compounds were consistently present, and specific, to the extracts of male beetles: $(R)-2$ methyl-1-butanol, $(R)$-3-hydroxy2-hexanone, and 2,3-hexanedione (1). The remaining compounds, present in extracts from both sexes, are system contaminants, found in the ambient air where the aerations were performed

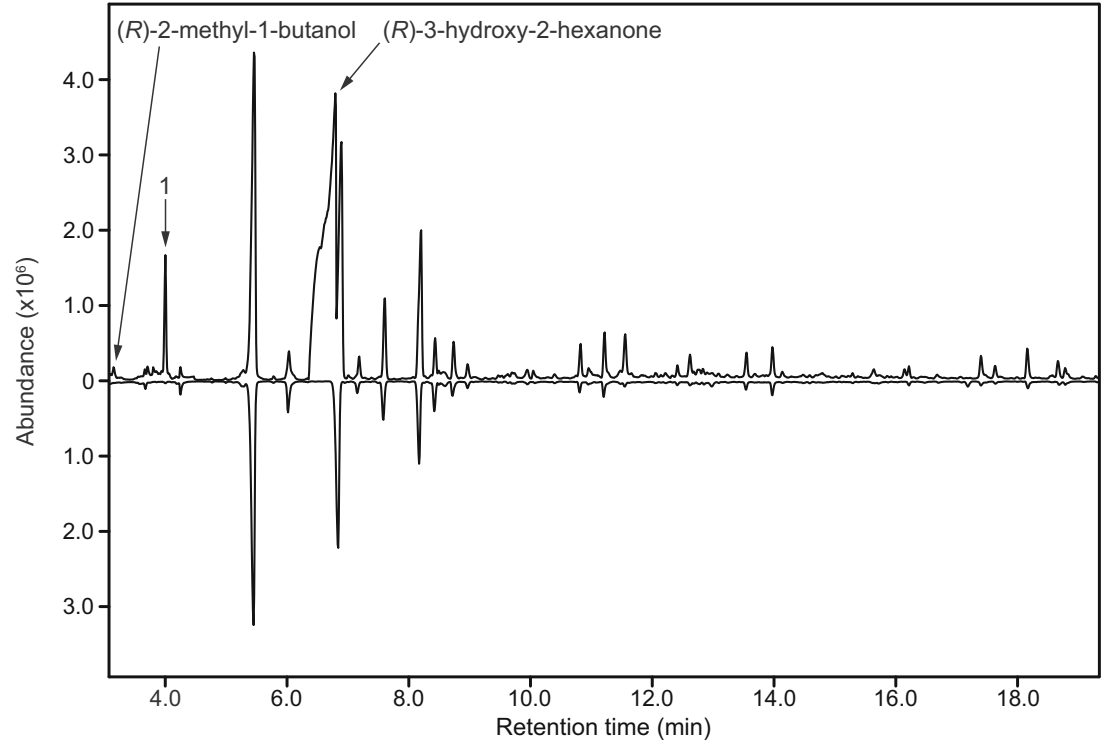

compounds (Fig. 4a) (for details on all post hoc tests, see Supplementary Table 2). Further, the traps captured a total of $45 P$. alni, and this species exhibited a similar pattern of attraction to that of $P$. sanguineum. However, only the mean catch for the 10:50 blend was significantly higher than the control (Fig. 4b). No other treatments differed significantly from each other. In contrast, $P$. testaceus exhibited a different pattern of trap catches. A total of 166 beetles were caught, and all treatments, except 3-hydroxy-2-hexanone as a single component, attracted significantly more beetles than the control, but none of the treatments were significantly different from each other (Fig. 4c).
In the second bioassay (2017), both $P$. sanguineum (1528 individuals) and $P$. alni (787 individuals) were captured in much higher total numbers than in bioassay 1. Pyrrhidium sanguineum was significantly more attracted to all binary blends compared to the control and 2-methyl-1-butanol as a single component (Fig. 5a). The 10:50 and 25:50 blends also captured significantly more beetles than 3-hydroxy-2-hexanone as a single component, but the 40:50 blend did not differ significantly from 3-hydroxy-2-hexanone as a single component, and the three blends did not differ significantly

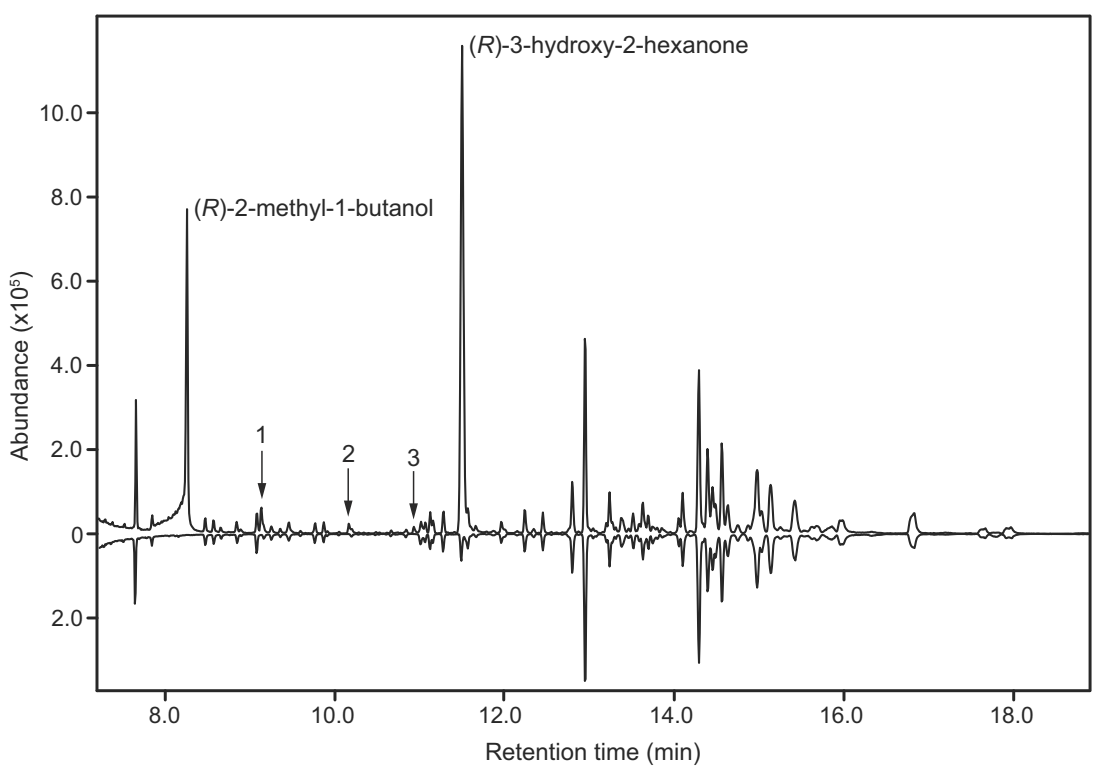

Fig. 3 GC-MS analysis of extracts of headspace volatiles from male (top trace) and female (bottom, inverted trace) P. alni (HP-5 MS column). Two insect-produced compounds occurred in large quantities and were specific to the extracts of male beetles: $(R)$-2-methyl-1-butanol and $(R)-3$-hydroxy-2-hexanone. In addition, minor quantities of three other compounds were present in the extracts of male beetles, but did not occur in the corresponding extracts of females, including 2,3-hexanedione (1), 2methyl-1-pentanol (2) and 1-hexanol (3). The remaining compounds, present in extracts from both sexes, are system contaminants, found in the ambient air where the aerations were performed (the compound in the extract from females with the same retention time as $(R)$-3-hydroxy-2hexanone is styrene) 

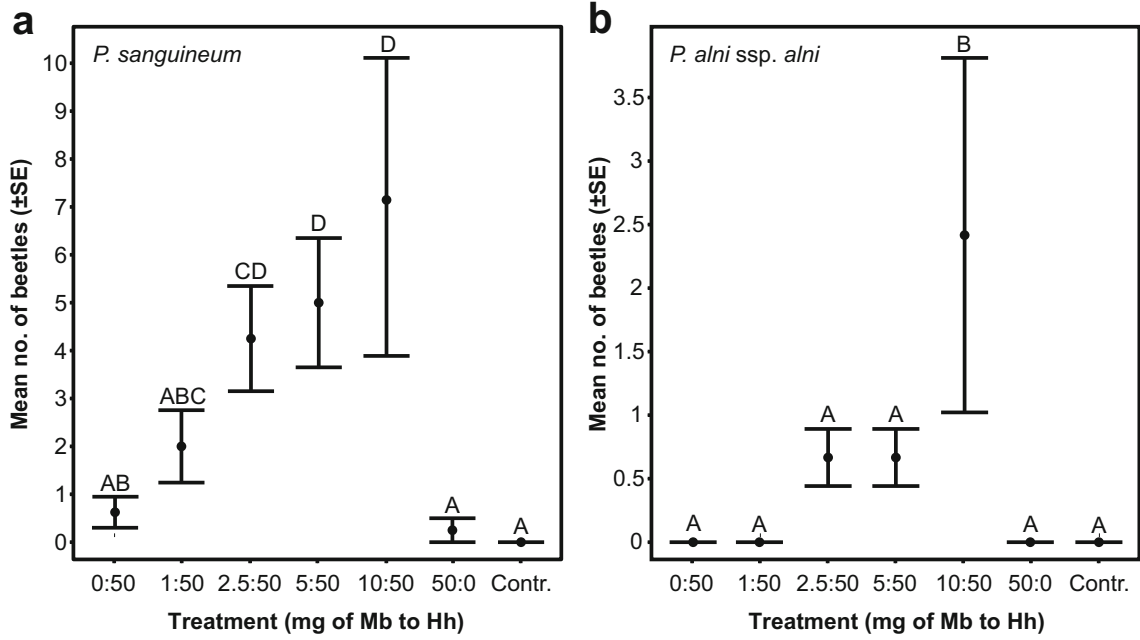

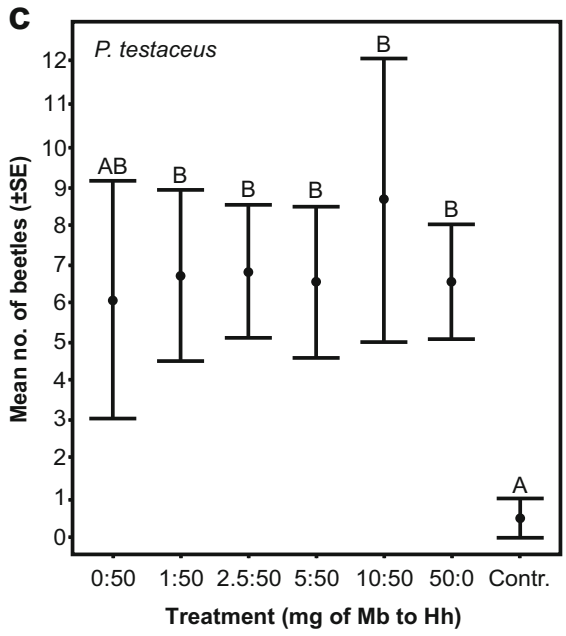

Fig. 4 Results from field trapping of $P$. sanguineum (a), P. alni (b) and P. testaceus (c) in bioassay 1 (2013). The mean number of captured beetles per trap and collection date is presented for different lure treatments. The lures consisted of different quantities $(\mathrm{mg})$ of racemic

from each other (Fig. 5a). The treatment with 3-hydroxy2-hexanone as a single component captured significantly more beetles compared to the control or 2-methyl-1butanol as a single component. For $P$. alni, attraction to all binary blends was significantly higher than to the control or the individual compounds, but the three blends were not significantly different from each other (Fig. 5b). The individual compounds did not differ from the control. Roughly the same number of P. testaceus (162 individuals) were captured in the second bioassay. Similar to bioassay 1 , all treatments attracted significantly more beetles than the control, but none of the treatments differed from each other (Fig. 5c). 2-methyl-1-butanol $(\mathrm{Mb})$ and racemic 3-hydroxy-2-hexanone $(\mathrm{Hh})$ in $0.5 \mathrm{ml}$ of isopropanol. Controls were baited with $0.5 \mathrm{ml}$ of isopropanol alone. Treatments that do not share a common letter are significantly different (adjusted $P<0.05$ ) (for details, see Supplementary Table 2)

Examination of the sex ratios of beetles caught in bioassay 2 revealed that catches consisted of both males and females of all species at about even ratios. The sex ratio was $55 \%$ males and $45 \%$ females from a sample of 183 P. sanguineum (from a trap with a $25: 50$ blend, first count), and 38\% males and $62 \%$ females from a sample of 135 P. alni (from a trap with a 40:50 blend, second count). For P. testaceus, 18 beetles from 6 traps baited with $50 \mathrm{mg}$ 2-methyl-1-butanol alone were $39 \%$ males and $61 \%$ females (third count), 25 beetles from 6 traps baited with $50 \mathrm{mg}$ 3-hydroxy-2-hexanone alone were $52 \%$ males and $48 \%$ females (third count), and 30 beetles from 6 traps baited with a $25: 50$ blend were $37 \%$ males and $63 \%$ females (third count).

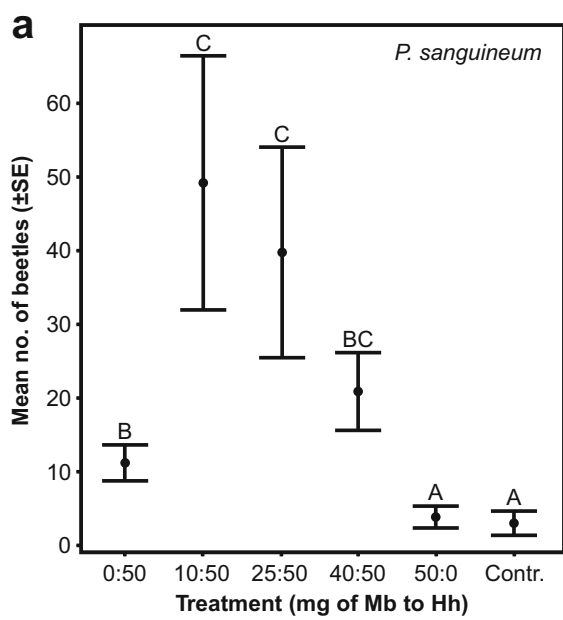

Fig. 5 Results from field trapping of $P$. sanguineum (a), P. alni (b) and $P$. testaceus (c) in bioassay 2 (2017). The mean number of captured beetles per trap and collection date is presented for different lure treatments. The lures consisted of different quantities $(\mathrm{mg})$ of racemic 2-methyl-1-butanol $(\mathrm{Mb})$ and racemic 3-hydroxy-2-hexanone $(\mathrm{Hh})$ in
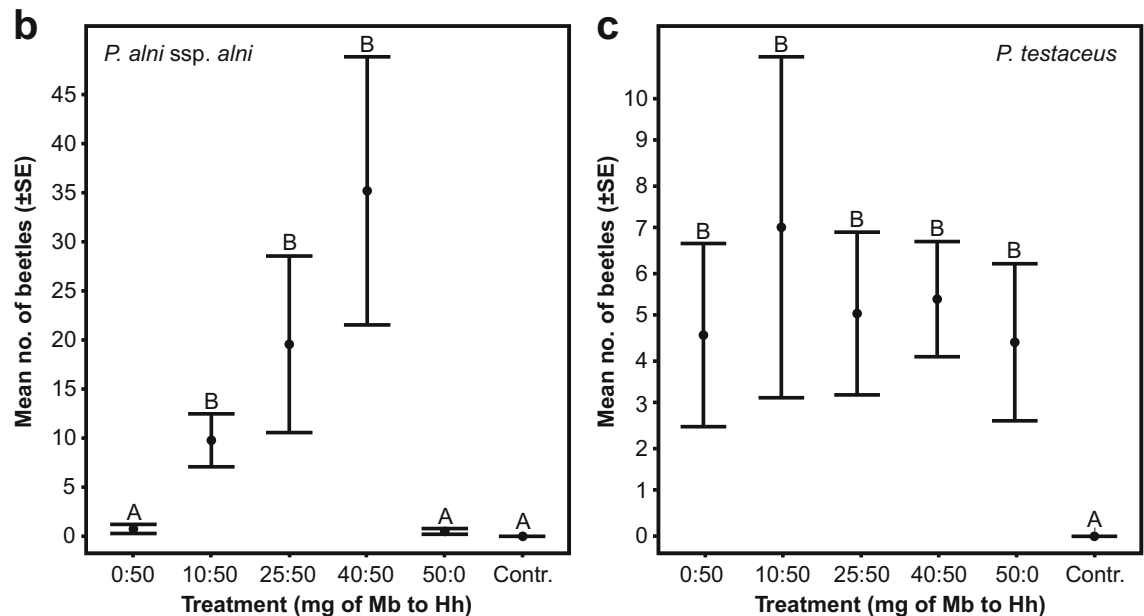

$0.5 \mathrm{ml}$ of isopropanol. The controls were baited with $0.5 \mathrm{ml}$ of isopropanol alone. Treatments that do not share a common letter are significantly different (adjusted $P<0.05$ ) (for details, see Supplementary Table 2) 


\section{Discussion}

Our study demonstrates that the male-produced aggregationsex pheromone blends of the longhorn beetles $P$. sanguineum and $P$. alni consist of $(R)$-3-hydroxy-2-hexanone and $(R)-2$ methyl-1-butanol. The minor component, 2-methyl-1-butanol, was not reported as a component of the volatiles produced by male $P$. sanguineum in a previous study (Schröder et al. 1994; Schröder 1996). In the work presented here, we first obtained evidence for two possible pheromone components in P. sanguineum from GC-EAD analyses of headspace volatiles, and then followed up with identification and field testing of the two compounds, demonstrating that $(R)$-2-methyl-1-butanol was indeed a key pheromone component for $P$. sanguineum, in addition to $(R)$-3-hydroxy-2-hexanone. In the previous work, Schröder et al. (1994) reported $(R)$-3-hydroxy-2-hexanone as the main pheromone component, but the extracts of males also contained trace quantities of $(2 R, 3 R)$ 2,3-hexanediol and (2S,3R)-2,3-hexanediol, in addition to 1butanol, 2,3-hexanedione and both enantiomers of 2-hydroxy3-hexanone (Fettköther 1995; Schröder 1996). The latter two compounds were likely artefacts formed by degradation of (R)-3-hydroxy-2-hexanone under the GC conditions used (Millar and Hanks 2017; Schröder et al. 1994), and we too noted the presence of these compounds during our work (depending on the temperatures used for GC analyses). However, we did not detect the hexanediols or 1-butanol in our extracts. In wind tunnel experiments, unmated females of $P$. sanguineum (but not males) had been shown to be significantly attracted to a synthetic four-component blend of $(R)-3$ hydroxy-2-hexanone, the 2,3-hexanediols and 2,3hexanedione, as well as $(R)$-3-hydroxy-2-hexanone as a single compound, respectively (Fettköther 1995; Schröder 1996). The most important compound for attraction in the wind tunnel assays appeared to be ( $R$ )-3-hydroxy-2-hexanone, as 2,3hexanedione alone and a mixture of the two hexanediols, were either not (2,3-hexanedione), or only weakly attractive (the mixture of hexanediols) to the unmated females (Fettköther 1995). 2-Hydroxy-3-hexanone and 1-butanol were not tested in the wind tunnel experiments (Fettköther 1995). Significant attraction to 3-hydroxy-2-hexanone as a single compound was also shown in one of our bioassays, but in general $P$. sanguineum was significantly more attracted to blends of 3-hydroxy-2-hexanone and 2-methyl-1-butanol than to either compound alone. This result is similar to the observations from two independent field bioassays conducted in Hungary (Imrei et al. 2013) and Sweden (IBW et al., unpubl. data), where single compounds were not significantly attractive to this species. The potential importance of the 2,3-hexanediols and 1-butanol for attraction remains unclear, but they are evidently not needed to achieve significant attraction.

In contrast to the other two species, for which the single components elicited no significant (or comparatively weak) attraction, $P$. testaceus was attracted to both 2-methyl-1butanol and 3-hydroxy-2-hexanone as single compounds (although the response to the hydroxyketone alone was not significant in 2013), and to all the blends of the two compounds (total range of ratios 2:100 to 80:100). No apparent additive or synergistic effects were obtained from blending the two components, contrary to what was observed for the two other species. Attraction of P. testaceus to 2-methyl-1-butanol is consistent with its previously reported pheromone chemistry, because males have been shown to produce $(R)$-2-methyl-1-butanol (Hanks et al. 2019), but the response to the hydroxyketone alone, which this species does not produce, is more difficult to explain. However, the observation is far from unique. Sweeney et al. (2014) reported significant attraction of $P$. testaceus to traps baited with a combination of the hydroxyketone and ethanol, and in recent studies in Poland and Italy, P. testaceus was significantly attracted to "multi-lure" blends that included racemic 3-hydroxy-2-hexanone, but not 2methyl-1-butanol (although additional compounds were present in the multi-lures; Flaherty et al. 2019; Rassati et al. 2019). Field studies conducted in the eastern USA, where P. testaceus was introduced many decades ago (Swift and Ray 2010), have revealed inconsistent responses to the two compounds. For example, adults of $P$. testaceus were attracted in significant numbers to traps baited with 3-hydroxy-2-hexanone alone during bioassays that lacked a 2-methyl-1-butanol treatment, but only the latter compound was attractive when both compounds were presented as single compound treatments in other bioassays (Hanks and Millar 2013; Hanks et al. 2018, 2019; Millar et al. 2018). Other field trials conducted in the eastern USA, with traps baited with blends of cerambycid pheromones that included 2-methyl-1-butanol and 3-hydroxy-2-hexanone (Handley et al. 2015; Hanks and Millar 2013), have also demonstrated significant attraction of $P$. testaceus to these blends. More comprehensive studies are needed to determine if P. testaceus has a preference for its own pheromone component or the heterospecific hydroxyketone, and how preference might be affected by different conditions.

In a wider perspective, insect sex or aggregation-sex pheromones are commonly assumed to be species-specific signals bringing individuals of the opposite sex together for mating (Cardé 2014). In cerambycid beetles, however, there appears to be a range of specificity, from rather promiscuous crossattraction of a number of species to a single component or blend, to attraction of only a single species (Millar and Hanks 2017). For the species studied here, the potential for cross-attraction among species is considerable, based on the identified pheromone blends and observed trap catches. Furthermore, both 3-hydroxy-2-hexanone and 2-methyl-1butanol are common pheromone components that are utilized by many other species in the subfamily Cerambycinae (Hanks and Millar 2016). Thus, in field bioassays, attraction of several longhorn beetle species to a single synthetic pheromone 
component, or a blend of components, is a common phenomenon (Mitchell et al. 2015). A possible explanation for the attraction of $P$. testaceus to the heterospecific pheromone component 3-hydroxy-2-hexanone is that there may be adaptive reasons for eavesdropping on the pheromonal signals of other guild members. For example, heterospecific signals could be exploited as cues to locate relatively scarce and ephemeral breeding substrates (see Hanks et al. 2007; Molander and Larsson 2018). Cross-attraction between heterospecific blends could be exacerbated by the fact that many cerambycine beetles appear to be relatively indifferent to the presence of the opposite enantiomers, with racemic mixtures often being as attractive as the insect-produced enantiomers (e.g., Hanks et al. 2019).

In our study, all three species were attracted to the same compounds, and differences in the blend ratios of 3-hydroxy-2-hexanone and 2-methyl-1-butanol only appear to constitute weak barriers to cross-attraction among the species. However, accumulating evidence suggests that many cerambycid species have relatively specific seasonal and diel activity patterns (Meier et al. 2019; Mitchell et al. 2015), only producing or responding to pheromones during specific time windows, providing additional mechanisms by which cross-attraction can be avoided, even among species with identical pheromones. Such subtleties may be obscured in trials with pheromone-baited traps, the lures of which release pheromones continuously, rather than only during discrete time windows. In fact, some separation of our species may occur due to different circadian rhythms because $P$. sanguineum and $P$. alni are primarily diurnal, whereas $P$. testaceus is predominantly crepuscular and/or nocturnal (LMH, MAM pers. obs.). The crepuscular/nocturnal habits of the latter species may also explain why we did not observe live P. testaceus in the emergence boxes, which were only inspected during the day. The seasonal phenologies of the three species are also partially separated, but the degree of overlap is substantial, particularly between $P$. sanguineum and P. alni. Typically, P. sanguineum emerges in late April in Sweden, with an activity peak around 20th May, whereas $P$. alni starts to emerge after the first week of May, with activity peaking in the first week of June. Similarly, P. testaceus starts to emerge in early June and has an activity peak in the first week of July (Lindhe et al. 2010). Furthermore, the substrates used by the three species in this study are superficially similar, but could provide some degree of separation at a fine scale. Phymatodes alni utilizes thin twigs (1-2.5 $\mathrm{cm} \varnothing)$ for oviposition, whereas $P$. sanguineum and $P$. testaceus primarily use somewhat larger branches and tree trunks $(\varnothing>5 \mathrm{~cm})$ (Ehnström and Holmer 2007; MAM pers. obs.). In addition, whereas $P$. sanguineum and $P$. aln $i$ breed almost exclusively in oak in Sweden, $P$. testaceus will readily colonize several other deciduous trees, although oak is the primary host (Ehnström and Holmer 2007). Phymatodes testaceus also appears to prefer more desiccated wood and bark compared to the two other species (Ehnström and Holmer 2007).

A common feature in male-produced aggregation-sex pheromone systems is that they are frequently centered on attraction towards valuable breeding substrates, whose kairomonal cues combine with the pheromone to form an integral part of the overall attractive signal (Landolt and Philips 1997; Schlyter and Birgersson 1999). This phenomenon has also been observed with a number of cerambycid species, where the male-produced aggregation-sex pheromones act synergistically with host plant volatiles (e.g., Collignon et al. 2016; many Monochamus spp., reviewed in Hanks and Millar 2016). It remains to be determined whether host volatiles may act additively or synergistically with our study species. Some or all of the above factors may contribute to reproductive isolation among these species, and further research is needed to elucidate the mechanisms involved and their relative importance.

For the purpose of monitoring saproxylic insect species as indicators of the effects of forest management and landscape change, it would be beneficial to monitor a broad range of species with different niche requirements, such as different host tree species, different dimensions of wood substrates, and different decomposition stages of woody material. At present, the lack of effective monitoring tools remains the most severe bottleneck for implementing large-scale conservation monitoring of endangered saproxylic insects. Thus, the fact that compounds are often shared, and the indifference to the presence of the "unnatural" enantiomer of a pheromone component, is fortuitous from a practical perspective, and should be viewed as an advantage, because it allows the simultaneous monitoring of several target species with the same lure and trap. For example, in the present study we identified a blend that attracts three cerambycid species representing different, but overlapping, substrate niches and host tree specificities among ephemeral substrates associated with fresh deadwood resources of oak. As suggested by the bioassay data from 2017, a suitable trade-off to monitor these species efficiently appears to be a 50:100 blend of the racemates of 2-methyl-1-butanol and 3-hydroxy-2hexanone, because all three species were significantly attracted to this blend. With pheromone-based monitoring as an effective sampling tool, these species may constitute cost-efficient model species as indicators of variation in the availability of fresh deadwood resources in managed forests. This in turn will provide an assessment of the suitability of different management regimes for conserving the deadwood resources required as host material by these and many other saproxylic species. 
Acknowledgements The authors wish to thank Björn Eriksson for help with statistics, and Marcus Vestlund and Jan Haikara for assistance during the field work. The Stina Werner Foundation at Gö and the forest company Sveaskog (Jan Dahl and Per Petersson) kindly gave us permission to work on their properties, and we thank the Blekinge County Administrative Board for permission to work within Gö nature reserve. Göran Birgersson offered helpful support with the GC-MS and GC-EAD instrumentation at the SLU Alnarp Campus. Jonas Helgesson at Helgesson Trädtjänst AB, Stefan Ekroth, Gunnar Isacsson, and forest companies Stora Enso and Södra Skogsägarna, made significant contributions to the supply of oak wood substrates. Konrad Dettner helped us gain access to a non-electronic reference. The project was financed by research grants (to MCL) from the Swedish Forest Society Foundation (grant numbers: 1011-84/150-7 HJHIL, and 2016-029 LOMOL), Ekfrämjandet: Erik Stenström Foundation (grant: 2015-5), WWF Sweden (grant: Insight: SWE 0163; Local: 500 131) the Swedish Environmental Protection Agency (grant: NV-03135-14), The Research Council Formas (grant: 2016-01372), the Royal Swedish Academy of Sciences (to MAM, grant: BS2015-0065), and the United States Department of Agriculture, Animal and Plant Health Inspection Service (to JGM and LMH, grant \# 14-, 15-, 16-, 17, and 18-8130-1422-CA).

\section{Compliance with Ethical Standards}

Conflict of Interest The authors declare that they have no conflicts of interest.

Open Access This article is distributed under the terms of the Creative Commons Attribution 4.0 International License (http:// creativecommons.org/licenses/by/4.0/), which permits unrestricted use, distribution, and reproduction in any medium, provided you give appropriate credit to the original author(s) and the source, provide a link to the Creative Commons license, and indicate if changes were made.

\section{References}

Allison JD, Borden JH, Seybold SJ (2004) A review of the chemical ecology of the Cerambycidae (Coleoptera). Chemoecology 14: 123-150. https://doi.org/10.1007/s00049-004-0277-1

ArtDatabanken (2015) The 2015 Swedish Red List. Swedish Species Information Centre, Uppsala

Barbour JD, Millar JG, Rodstein J, Ray AM, Alston DG, Rejzek M, Dutcher JD, Hanks LM (2011) Synthetic 3,5-dimethyldodecanoic acid serves as a general attractant for multiple species of Prionus (Coleoptera: Cerambycidae). Ann Entomol Soc Am 104:588-593. https://doi.org/10.1603/AN10182

Bates D, Mächler M, Bolker BM, Walker SC (2015) Fitting linear mixedeffects models using lme4. J Stat Softw 67:1-48. https://doi.org/10. 18637/jss.v067.i01

Buse J, Ranius T, Assmann T (2008) An endangered longhorn beetle associated with old oaks and its possible role as an ecosystem engineer. Cons Biol 22:329-337. https://doi.org/10.1111/j.1523-1739. 2007.00880.x

Cardé RT (2014) Defining attraction and aggregation pheromones: teleological versus functional perspectives. J Chem Ecol 40:519-520. https://doi.org/10.1007/s10886-014-0465-6

Collignon RM, Swift IP, Zou Y, McElfresh S, Hanks LM, Millar JG (2016) The influence of host plant volatiles on the attraction of longhorn beetles to pheromones. J Chem Ecol 42:215-229. https:// doi.org/10.1007/s10886-016-0679-x
Ehnström B, Holmer M (2007) Nationalnyckeln till Sveriges flora och fauna. Skalbaggar: Långhorningar. Coleoptera: Cerambycidae. Swedish Species Information Centre, Uppsala

Fettköther R (1995) Die exokrinen Drüsensysteme der Bockkäfer (Coleoptera, Cerambycidae): Experimentelle Ansätze zur Klärung der biologischen Funktionen der Prothorakaldrüse sowie der sternalen Metathorakal- und Abdominaldrüse. Dissertation, Unieversity of Bayreuth

Flaherty L, Gutowski JMG, Hughes C, Mayo P, Mokrzycki T, Pohl G, Silk P, Van Rooyen K, Sweeney J (2019) Pheromone-enhanced lure blends and multiple trap heights improve detection of bark and wood-boring beetles potentially moved in solid wood packaging. $\mathrm{J}$ Pest Sci 92:309-325. https://doi.org/10.1007/s10340-018-1019-4

Graham EE, Poland TM (2012) Efficacy of fluon conditioning for capturing cerambycid beetles in different trap designs and persistence on panel traps over time. J Econ Entomol 105:395-401. https://doi. org/10.1603/EC11432

Haack RA (2017) Cerambycid pests in forests and urban trees. In: Wang Q (ed) Cerambycidae of the world: biology and pest management. CRC Press/Taylor \& Francis Group, Boca Raton, pp 352-384

Handley K, Hough-Goldstein J, Hanks LM, Millar JG, D'Amico V (2015) Species richness and phenology of cerambycid beetles in urban forest fragments of northern Delaware. Ann Entomol Soc Am 108:251-262. https://doi.org/10.1093/aesa/sav005

Hanks LM, Millar JG (2013) Field bioassays of cerambycid pheromones reveal widespread parsimony of pheromone structures, enhancement by host plant volatiles, and antagonism by components from heterospecifics. Chemoecology 23:21-44. https://doi.org/10.1007/ s00049-012-0116-8

Hanks LM, Millar JG (2016) Sex and aggregation-sex pheromones of cerambycid beetles: basic science and practical applications. J Chem Ecol 42:631-654. https://doi.org/10.1007/s10886-016-0733-8

Hanks LM, Millar JG, Moreira JA, Barbour JD, Lacey ES, McElfresh JS, Reuter FR, Ray AM (2007) Using generic pheromone lures to expedite identification of aggregation pheromones for the cerambycid beetles Xylotrechus nauticus, Phymatodes lecontei, and Neoclytus modestus modestus. J Chem Ecol 33:889-907. https://doi.org/10. 1007/s10886-007-9275-4

Hanks LM, Mongold-Diers JA, Atkinson TH, Fierke MK, Ginzel MD, Graham EE, Poland TM, Richards AB, Richardson ML, Millar JG (2018) Blends of pheromones, with and without host plant volatiles, can attract multiple species of cerambycid beetles simultaneously. J Econ Entomol 111:716-724. https://doi.org/10.1093/jee/tox373

Hanks LM, Mongold-Diers JA, Mitchell RF, Zou Y, Wong JCH, Meier LR, Johnson TD, Millar JG (2019) The role of minor pheromone components in segregating 14 species of longhorned beetles (Coleoptera: Cerambycidae) of the subfamily Cerambycinae. J Econ Entomol (in press). https://doi.org/10.1093/jee/toz141

Hansen (1966) Biller XXII. Træbukke. GEC Gads Forlag, Copenhagen

Hedin J, Isacsson G, Jonsell M, Komonen A (2008) Forest fuel piles as ecological traps for saproxylic beetles in oak. Scand J For Res 23: 348-357. https://doi.org/10.1080/02827580802269991

Hogstad O, Stenberg I (1997) Breeding success, nestling diet and parental care in the white-backed woodpecker Dendrocopus leucotos. J Ornithol 138:25-38. https://doi.org/10.1007/BF01651649

Imrei Z, Millar JG, Janik G, Tóth M (2013) Field screening of known pheromone components of longhorned beetles in the subfamily Cerambycinae (Coleoptera: Cerambycinae) in Hungary. Z für Naturforschung C 68:236-242. https://doi.org/10.1515/znc-20135-610

Jeppsson T, Lindhe A, Gärdenfors U, Forslund P (2010) The use of historical collections to estimate population trends: a case study using Swedish longhorn beetles (Coleoptera: Cerambycidae). Biol Conserv 143:1940-1950. https://doi.org/10.1016/j.biocon.2010.04.015

Lacey ES, Moreira JA, Millar JG, Ray AM, Hanks LM (2007) Maleproduced aggregation pheromone of the cerambycid beetle 
Neoclytus mucronatus mucronatus. Entomol Exp Appl 122:171179. https://doi.org/10.1111/j.1570-7458.2006.00508.x

Lenth R (2018) Emmeans: estimated marginal means, aka least-squares means. R package version 1.2.1. https://CRAN.R-project.org/ package $=$ emmeans. Accessed 10 Oct 2018

Landolt PJ, Philips TW (1997) Host plant influences on sex pheromone behavior of phytophagous insects. Annu Rev Entomol 42:371-391. https://doi.org/10.1146/annurev.ento.42.1.371

Larsson MC (2016) Pheromones and other semiochemicals for monitoring rare and endangered species. J Chem Ecol 42:853-868. https:// doi.org/10.1007/s10886-016-0753-4

Lindhe A, Jeppsson T, Ehnström B (2010) Longhorn beetles in Sweden changes in distribution and abundance over the last two hundred years. Entomologisk Tidskrift 131:241-510

Linsley EG (1959) Ecology of Cerambycidae. Annu Rev Entomol 4:99_ 138. https://doi.org/10.1146/annurev.en.04.010159.000531

Meier LR, Millar JG, Mongold-Diers JA, Hanks LM (2019) (S)-Sulcatol is a pheromone component for two species of cerambycid beetles in the subfamily Lamiinae. J Chem Ecol 45:447-454. https://doi.org/ 10.1007/s10886-019-01071-7

Milberg P, Bergman K-O, Sancak K, Jansson N (2016) Assemblages of saproxylic beetles on large downed trunks of oak. Ecol Evol 6: 1614-1625. https://doi.org/10.1002/ece3.1935

Millar JG, Hanks LM (2017) Chemical ecology of cerambycids. In: Wang Q (ed) Cerambycidae of the world: biology and pest management. CRC Press/Taylor \& Francis Group, Boca Raton, pp 161-208

Millar JG, Mitchell RF, Mongold-Diers JA, Zou Y, Bográn CE, Fierke MK, Ginzel MD, Johnson CW, Meeker JR, Poland TM, Ragenovich I, Hanks LM (2018) Identifying possible pheromones of cerambycid beetles by field testing known pheromone components in four widely separated regions of the United States. J Econ Entomol 111:252259. https://doi.org/10.1093/jee/tox312

Mitchell RF, Reagel PF, Wong JC, Meier LR, Silva WD, Mongold-Diers J, Millar JG, Hanks LM (2015) Cerambycid beetle species with similar pheromones are segregated by phenology and minor pheromone components. J Chem Ecol 41:431-440. https://doi.org/10. 1007/s10886-015-0571-0

Molander MA, Larsson MC (2018) Identification of the aggregation-sex pheromone of the cerambycid beetle Phymatodes pusillus ssp. pusillus and evidence of a synergistic effect from a heterospecific pheromone component. J Chem Ecol 44:987-998. https://doi.org/ 10.1007/s10886-018-1008-3

Molander MA, Helgesson J, Winde IB, Millar JG, Larsson MC (2019) The male-produced aggregation-sex pheromone of the cerambycid beetle Plagionotus detritus ssp. detritus. J Chem Ecol 45:28-36. https://doi.org/10.1007/s10886-018-1031-4

R Core Team (2018) R: A language and environment for statistical computing. R Foundation for statistical computing. https://www.Rproject.org/. Accessed 6 Sept 2018

Ranius T, Jansson N (2000) The influence of forest regrowth, original canopy cover and tree size on saproxylic beetles associated with old oaks. Biol Conserv 95:85-94. https://doi.org/10.1016/S00063207(00)00007-0

Rassati D, Marini L, Marchioro M, Rapuzzi P, Magnani G, Poloni R, Giovanni FD, Mayo P, Sweeney J (2019) Developing trapping protocols for wood-boring beetles associated with broadleaf trees. J Pest Sci 92:267-279. https://doi.org/10.1007/s10340-018-0984-y

Ray AM, Barbour JD, McElfresh JS, Moreira JA, Swift I, Wright IM, Žunič A, Mitchell RF, Graham EE, Alten RL, Millar JG, Hanks LM (2012) 2,3-Hexanediols as sex attractants and a female-produced sex pheromone for cerambycid beetles in the prionine genus Tragosoma. J Chem Ecol 38:1151-1158. https://doi.org/10.1007/ s10886-012-0181-z

Ray AM, Arnold RA, Swift I, Schapker PA, McCann S, Marshall CJ, McElfresh JS, Millar JG (2014) (R)-Desmolactone is a sex pheromone or sex attractant for the endangered valley elderberry longhorn beetle Desmocerus californicus dimorphus and several congeners (Cerambycidae: Lepturinae). PLoS One 9:e115498. https://doi.org/ 10.1371/journal.pone.0115498

Schlyter F, Birgersson GA (1999) Forest beetles. In: Hardie J, Minks AK (eds) Pheromones of non-lepidopteran insects associated with agricultural plants. CABI Publishing, Wallingford, pp 113-148

Schröder FC (1996) Identifizierung und Synthese neuer Alkaloide, Hydroxyketone und bicyclischer Acetale aus Insekten. Dissertation, University of Hamburg

Schröder F, Fettköther R, Noldt U, Dettner K, König WA, Francke W (1994) Synthesis of (3R)-3-hydroxy-2-hexanone, $(2 R, 3 R)-2,3$ hexanediol and $(2 S, 3 R)-2,3$-hexanediol, the male sex pheromone of Hylotrupes bajulus and Pyrrhidium sanguineum (Cerambycidae). Liebigs Annalen der Chemie 1994:1211-1218. https://doi.org/10.1002/jlac.199419941212

Seibold S, Brandl R, Buse J, Hothorn T, Schmidl J, Thorn S, Müller J (2015) Association of extinction risk of saproxylic beetles with ecological degradation of forests in Europe. Cons Biol 29:382-390. https://doi.org/10.1111/cobi.12427

Sweeney JD, Silk PJ, Grebennikov V (2014) Efficacy of semiochemicalbaited traps for detection of longhorn beetles (Coleoptera: Cerambycidae) in the Russian Far East. Eur J Entomol 111:397406. https://doi.org/10.14411/eje.2014.049

Swift IP, Ray AM (2010) Nomenclatural changes in North American Phymatodes Mulsant (Coleoptera: Cerambycidae). Zootaxa 2448: 35-52. https://doi.org/10.11646/zootaxa.2448.1.3

Wind P, Pihl S (2010) The Danish Red List. The National Environmental Research Institute, Århus. http://bios.au.dk/en/consultancy/nature/ the-danish-red-list/. Accessed 16 Nov 2018

Žunič Kosi A, Zou Y, Hoskovec M, Vrezec A, Stritih N, Millar JG (2017) Novel, male-produced aggregation pheromone of the cerambycid beetle Rosalia alpina, a priority species of European conservation concern. PLoS One 12:e0183279. https://doi.org/10.1371/journal. pone. 0183279 